\title{
Various subtypes of phosphodiesterase inhibitors differentially regulate pulmonary vein and sinoatrial node electrical activities
}

\author{
YUNG-KUO LIN $^{1,2^{*}}$, CHEN-CHUAN CHENG ${ }^{3 *}$, JEN-HUNG HUANG ${ }^{1,2}$, YI-ANN CHEN $^{4}$, \\ YEN-YU LU ${ }^{5}$, YAO-CHANG CHEN ${ }^{6}$, SHIH-ANN CHEN ${ }^{7}$ and YI-JEN CHEN ${ }^{1,8}$
}

\begin{abstract}
${ }^{1}$ Department of Internal Medicine, Division of Cardiovascular Medicine, Wan Fang Hospital; ${ }^{2}$ Department of Internal Medicine, Division of Cardiology, School of Medicine, College of Medicine, Taipei Medical University, Taipei 11696; ${ }^{3}$ Division of Cardiology, Chi-Mei Medical Center, Tainan 71004; ${ }^{4}$ Division of Nephrology; ${ }^{5}$ Division of Cardiology, Department of Internal Medicine, Sijhih Cathay General Hospital, New Taipei 22174; ${ }^{6}$ Department of Biomedical Engineering, National Defense Medical Center, Taipei 11490; ${ }^{7}$ Heart Rhythm Center and Division of Cardiology, Department of Medicine, Taipei Veterans General Hospital, Taipei $11217 ;{ }^{8}$ Graduate Institute of Clinical Medicine,

College of Medicine, Taipei Medical University, Taipei 11696, Taiwan, R.O.C.
\end{abstract}

Received May 16, 2019; Accepted January 9, 2020

DOI: $10.3892 /$ etm.2020.8495

\begin{abstract}
Phosphodiesterase (PDE)3-5 are expressed in cardiac tissue and play critical roles in the pathogenesis of heart failure and atrial fibrillation. PDE inhibitors are widely used in the clinic, but their effects on the electrical activity of the heart are not well understood. The aim of the present study was to examine the effects of various PDE inhibitors on spontaneous cardiac activity and compare those effects between sinoatrial nodes (SANs) and pulmonary veins (PVs). Conventional microelectrodes were used to record action potentials in isolated rabbit SAN and PV tissue preparations, before and after administration of different concentrations $(0.1,1$ and $10 \mu \mathrm{M})$ of milrinone (PDE3 inhibitor), rolipram (PDE4 inhibitor) and sildenafil (PDE5 inhibitor), with or without the application of isoproterenol (cAMP and PKA activator), KT5823 (PKG inhibitor) or H89 (PKA inhibitor). Milrinone (1 and $10 \mu \mathrm{M})$ increased the spontaneous activity in PVs by $10.6 \pm 4.9$ and $16.7 \pm 5.3 \%$ and in SANs by $9.3 \pm 4.3$ and
\end{abstract}

Correspondence to: Professor Yao-Chang Chen, Department of Biomedical Engineering, National Defense Medical Center, 161 Minquan E. Road, Taipei 11490, Taiwan, R.O.C.

E-mail: bme02@mail.ndmctsgh.edu.tw

Dr Yen-Yu Lu, Division of Cardiology, Department of Internal Medicine, Sijhih Cathay General Hospital, 59 Jiancheng Road, New Taipei 22174, Taiwan, R.O.C.

E-mail: yolu59@yahoo.com.tw

*Contributed equally

Key words: atrial fibrillation, phosphodiesterase inhibitor, pulmonary vein, sinoatrial node
$20.7 \pm 4.6 \%$, respectively. In addition, milrinone (1 and $10 \mu \mathrm{M})$ induced the occurrence of triggered activity (0/8 vs. $5 / 8$; $\mathrm{P}<0.005$ ) in PVs. Rolipram increased PV spontaneous activity by $7.5 \pm 1.3-9.5 \pm 4.0 \%$, although this was not significant, and did not alter SAN spontaneous activity. Sildenafil reduced spontaneous activity in PVs to a greater extent than that seen in SANs. Both KT5823 and H89 suppressed milrinone-increased PV spontaneous activity. In the presence of isoproterenol, milrinone did not alter isoproterenol-induced PV arrhythmogenesis, suggesting that the effects of PDE3 are mediated by the protein kinase $\mathrm{G}$ and protein kinase A signaling pathways. In conclusion, inhibitors of different PDE subtypes exert diverse electrophysiological effects on PV and SAN activities.

\section{Introduction}

Atrial fibrillation (AF) is the most common sustained cardiac arrhythmia that causes cardiac dysfunction and strokes (1). Heart failure (HF) is characterized by chamber dilatation, which may promote the occurrence of AF through mechanoelectrical feedback and electrical or structural remodeling (2-6). Different 3',5'-cyclic nucleotide phosphodiesterase (PDE) isozymes exert distinctive biological functions, therefore, pharmacological inhibition of these PDEs might offer novel therapeutic strategies through their abilities to modulate cardiovascular diseases, including HF $(7,8)$. In particular, PDE3-5 were reported to be expressed in cardiomyocytes and might play a role in both HF and AF $(7,8)$. The PDE3 inhibitor, milrinone, exerts positive inotropic, vasodilating and minimal chronotropic effects, which are expected to improve HF (9). However, milrinone has potentially fatal adverse effects, including ventricular arrhythmias, which limit its use (10-14). PDE4 is expressed by human atrial myocytes, and its D isoform (PDE4D) has been linked to stroke risk in a number of genome-wide association 
studies $(15,16)$. In a human study, PDE4 activity decreased by almost $50 \%$ in AF compared with patients with SR (17). Furthermore, cardiac PDE4D expression was also reduced in humans with atrial fibrillation, and a clinical trial revealed a slight increase in incidence of atrial arrhythmia in the PDE4 inhibitor (rofluminast)-treated group, suggesting that a decrease in PDE4 activity may be linked to the development of AF. The PDE5 inhibitor, sildenafil, blocks the L-type calcium current $\left(\mathrm{I}_{\mathrm{Ca}-\mathrm{L}}\right)$ and the human ether-a-go-go related gene potassium channel in ventricular myocytes $(18,19)$. Higher concentrations of sildenafil $(0.2 \mu \mathrm{g} / \mathrm{ml})$, with a nitric oxide (NO) donor, increase ventricular tachycardia or ventricular fibrillation, suggesting a potential risk of atrial arrhythmogenesis with the use of PDE5 inhibitors (20).

Pulmonary veins (PVs) form complex histological components with vascular structures and cardiomyocytes (21). PVs serve critical roles in AF initiation and maintenance through their distinctive electrical and structural properties (22-25). Furthermore, sinoatrial node (SAN) electrical activity can modulate PV arrhythmogenesis by increasing PVs spontaneous activity, and while PVs spontaneous activity exceeds SAN activity, atrial arrhythmia may occur (26). In addition to direct effects on cardiomyocytes, inhibitors of different PDE subtypes significantly regulate vascular activity, as well as cardiac contractility and pacemaker activity (7). Accordingly, it was hypothesized that PDE3-5 inhibitors may differentially regulate $\mathrm{PV}$ and $\mathrm{SAN}$ electrical activities, thereby contributing to the pathogenesis of AF. The present study aimed to investigate the effects and mechanisms of inhibitors of the three PDE subtypes on cardiac spontaneous activity in SANs and PVs.

\section{Materials and methods}

Rabbit PV and atrial tissue preparations. The present study was approved of the Institutional Animal Care and Use Committee (approval no. IACUC-19-124) of the National Defense Medical Center, Taipei, Taiwan and conformed to the institutional Guide for the Care and Use of Laboratory Animals and the 'Guide for the Care and Use of Laboratory Animals' published by the United States National Institutes of Health (8 ed. Washington DC, 2011). Male New Zealand white rabbits ( $n=47$; weight, $2.0-3.0 \mathrm{~kg}$; age, 6-8 months) were used in the present study. All of the rabbits had access to food and water ad libitum, and were maintained in a temperature and humidity-controlled environment $\left(20-22^{\circ} \mathrm{C}\right.$; $50-70 \%$ humidity) with a $12 \mathrm{~h}$ light/dark cycle, and were raised in stainless steel cages. After rabbits were euthanized using intramuscular injections of a mixture of Zoletil 50 $(10 \mathrm{mg} / \mathrm{kg})$ and xylazine $(5 \mathrm{mg} / \mathrm{kg})$ with an overdose of isoflurane (5\% in oxygen) from a precision vaporizer as previously described $(27,28)$. Hearts were rapidly removed and placed in perfusion fluid after a midline thoracotomy. To dissect the PV, the heart was opened by an incision along the mitral valve annulus, extending from the coronary sinus to the septum, in Tyrode's solution comprised of $137 \mathrm{mM}$ sodium chloride, $4 \mathrm{mM}$ potassium chloride, $15 \mathrm{mM}$ sodium bicarbonate, $0.5 \mathrm{mM}$ monosodium phosphate, $0.5 \mathrm{mM}$ magnesium chloride, $2.7 \mathrm{mM}$ calcium chloride and $11 \mathrm{mM}$ dextrose. The PV was separated from the atrium at the level of the left atrial-PV junction and separated from the lungs at the ending of the PV myocardial sleeve. The SAN was isolated from the right atrium. The adventitia or epicardial side of the preparation faced upwards. One end of the preparation, consisting of the PV and atrial-PV junction, was pinned with needles to the bottom of a tissue bath. The distal-PV was connected to a FT03C force transducer (Grass Instruments Co.) by silk threads. The PV tissue strips were superfused at a constant rate $(3 \mathrm{ml} / \mathrm{min})$ with Tyrode's solution and were saturated with a gas mixture of $97 \% \mathrm{O}_{2} / 3 \%$ $\mathrm{CO}_{2}$. The temperature was maintained at $37^{\circ} \mathrm{C}$ and the preparations were allowed to equilibrate for $1 \mathrm{~h}$ before the electrophysiological assessment.

Electrophysiological and pharmacological studies. Transmembrane action potentials (APs) of the PVs were recorded by machine-pulled glass capillary microelectrodes filled with $3 \mathrm{~mol} / \mathrm{K} \mathrm{KCl}$, which were connected to a Duo 773 electrometer (World Precision Instruments, Ltd.) under a tension of $1.47 \mathrm{mN}(150 \mathrm{mg})$. Electrical and mechanical events (contractile force and diastolic tension) were simultaneously displayed on a 4072 oscilloscope (Gould) and a TA11 recorder (Gould). Using a data acquisition system, signals were recorded with direct coupling and a filter with a $10-\mathrm{kHz}$ low-pass cut-off frequency. Signals were recorded digitally with a 16-bit accuracy, at a rate of $125 \mathrm{kHz}$. Electrical stimulation was provided using a Grass S88 stimulator through a SIU5B stimulus isolation unit (Grass Instruments Co.). Different concentrations of a PDE3 inhibitor (milrinone; 0.1, 1 and $10 \mu \mathrm{M}$; Sigma-Aldrich; Merck KGaA), PDE4 inhibitor (rolipram; 0.1, 1 and $10 \mu \mathrm{M}$; Sigma-Aldrich; Merck KGaA) or PDE5 inhibitor (sildenafil; $0.1,1$ and $10 \mu \mathrm{M}$; Sigma-Aldrich; Merck KGaA) were sequentially superfused to test for pharmacological responses. For each concentration, PV and SAN preparations were treated for at least $30 \mathrm{~min}$. The electrical activity in isolated rabbit PVs was recorded before and after the application of $10 \mu \mathrm{M}$ milrinone with or without isoproterenol (1 $\mu \mathrm{M}$; Sigma-Aldrich; Merck KGaA), KT5823 (1 $\mu \mathrm{M}$; Tocris Bioscience) [a potent selective inhibitor of cyclic guanosine monophosphate (cGMP)-dependent protein kinase G (PKG)] or H89 (a protein kinase A [PKA] inhibitor; $10 \mu \mathrm{M}$; Sigma-Aldrich; Merck KGaA) (29).

Spontaneous activity was defined as the constant occurrence of spontaneous APs in the absence of any electrical stimuli. Early afterdepolarizations (EADs) were defined as the interruption of the smooth contour of phase 2 or 3 of the APs. Delayed afterdepolarizations (DADs) were defined as the presence of a spontaneous hump-shaped depolarization of the impulse after full repolarization had occurred. Burst firing was defined as the occurrence of an accelerated spontaneous potential (faster than the basal rate) with sudden onset and termination.

Statistical analysis. All continuous variables are expressed as the mean \pm SEM. Repeated-measures ANOVA followed by Duncan's post hoc test was used to compare the difference before and after drug administration. Electrophysiological and mechanical characteristics were compared between different groups by a Wilcoxon rank-sum test or an unpaired t-test, depending on the outcome of the normality test. Nominal 
A
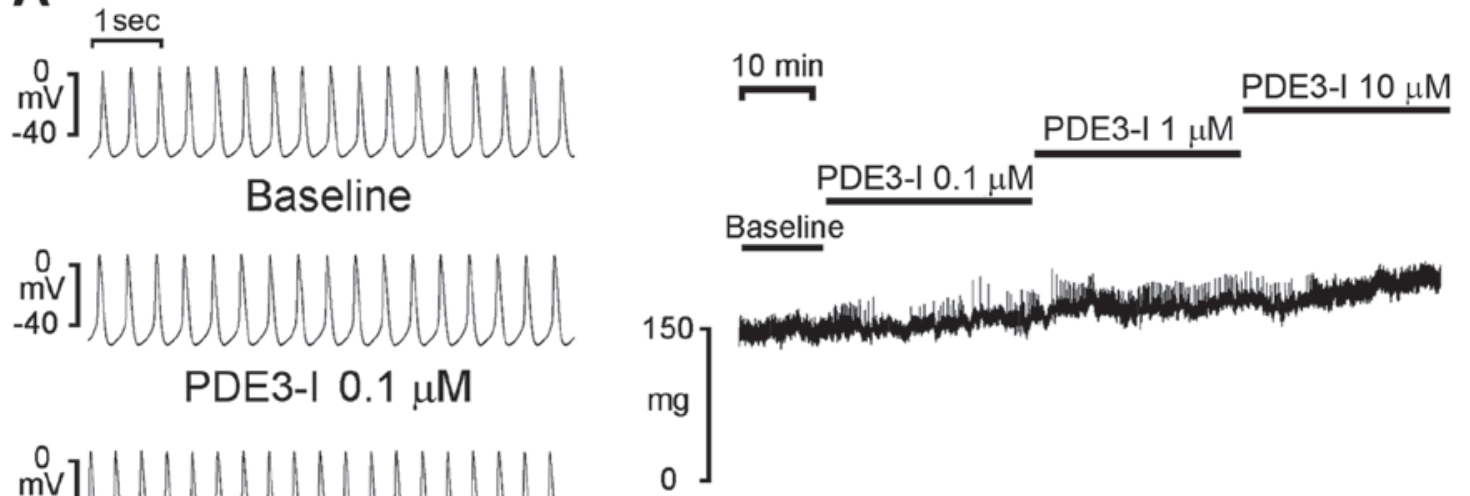

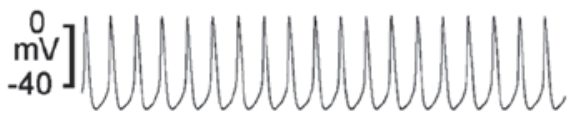

PDE3-I $1 \mu \mathrm{M}$

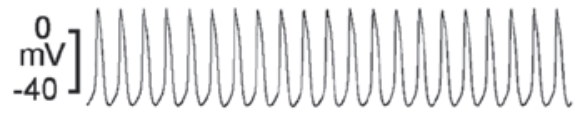

PDE3-I $10 \mu \mathrm{M}$

口Baseline $\quad$ PDE3-I $1 \mu \mathrm{M}$

-PDE3-I $0.1 \mu \mathrm{M}$-PDE3-I $10 \mu \mathrm{M}$
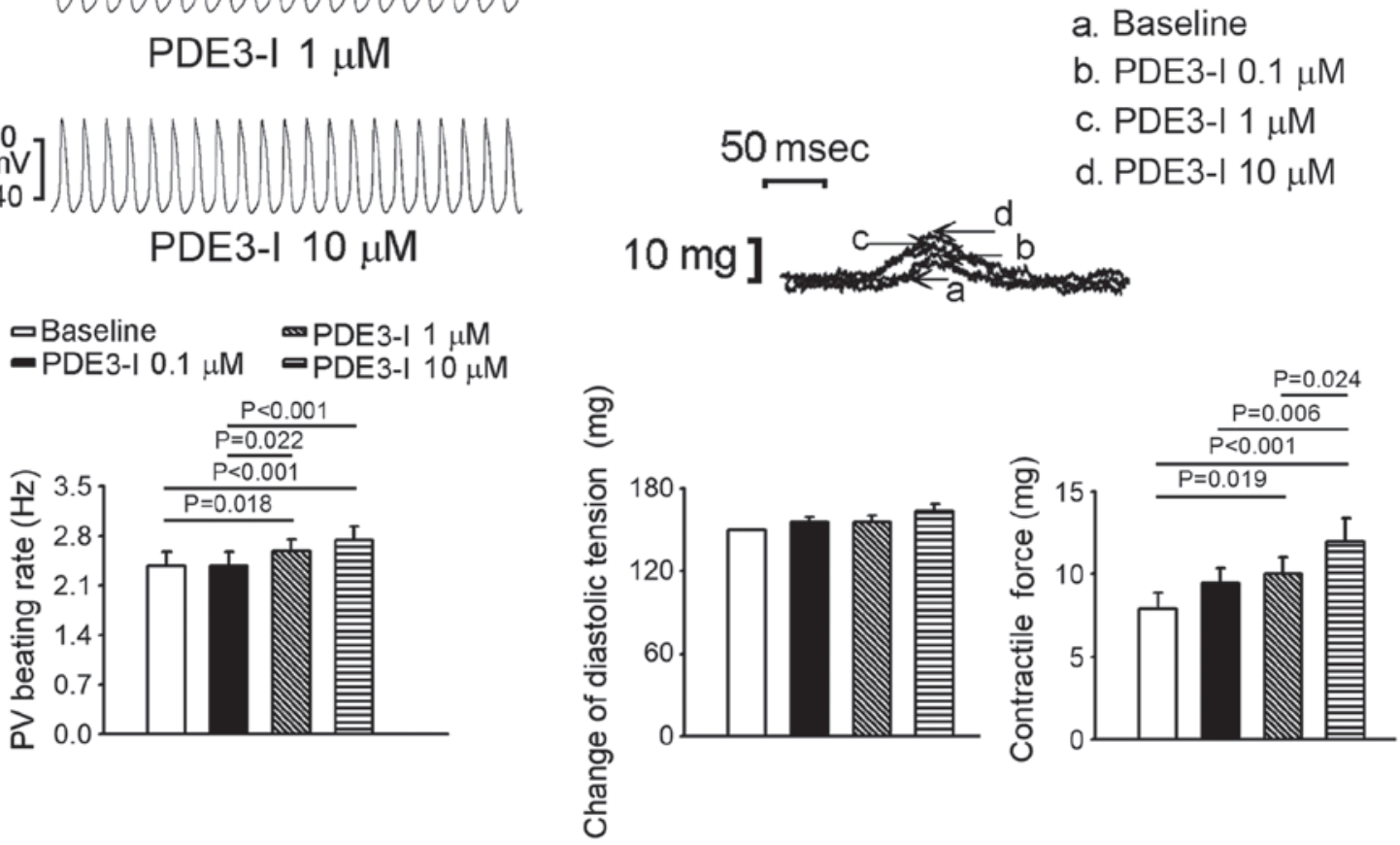

B

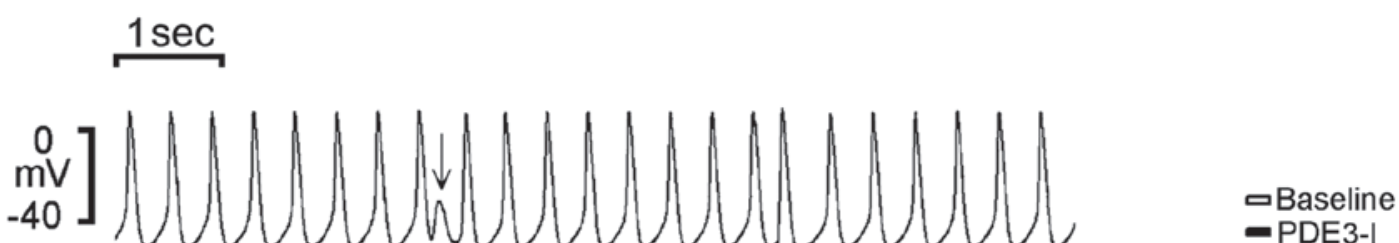

PDE3-I

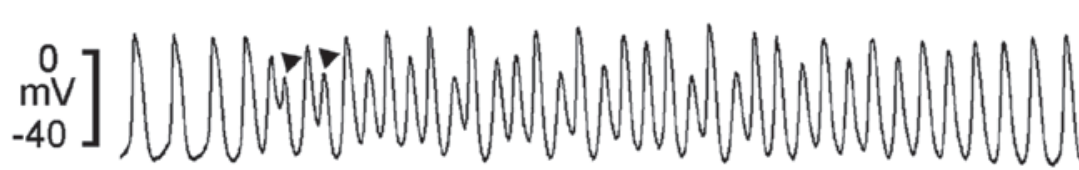

PDE3-I

*
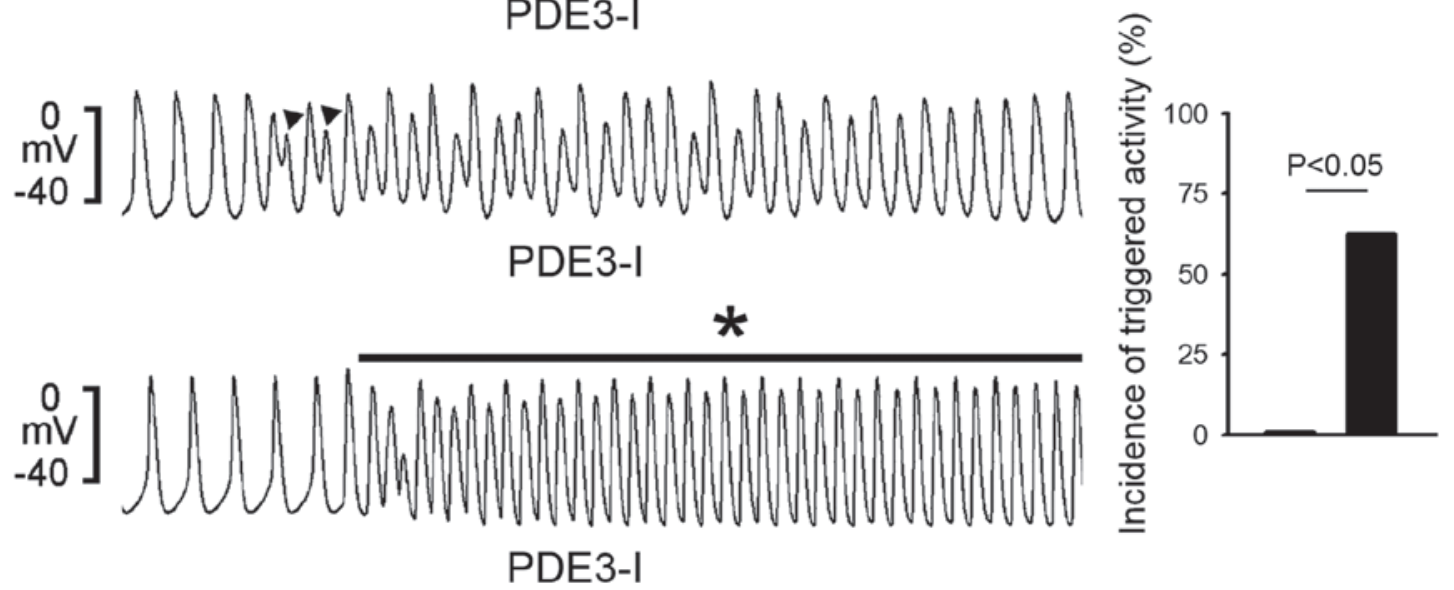

Figure 1. Effects of the PDE3 inhibitor (PDE3-I), milrinone, on the electrical activity of isolated PVs. (A) Representative data of the beating rate, diastolic tension and contractility of PVs after the application of different concentrations $(0.1,1$ and $10 \mu \mathrm{M})$ of the PDE3-I (n=8). (B) Representative data of the triggered activity of delayed afterdepolarizations (arrow), early afterdepolarizations (arrowheads) and burst firings (asterisk), induced by PDE3-I. PDE3, phosphodiesterase 3 ; PVs, pulmonary veins. 

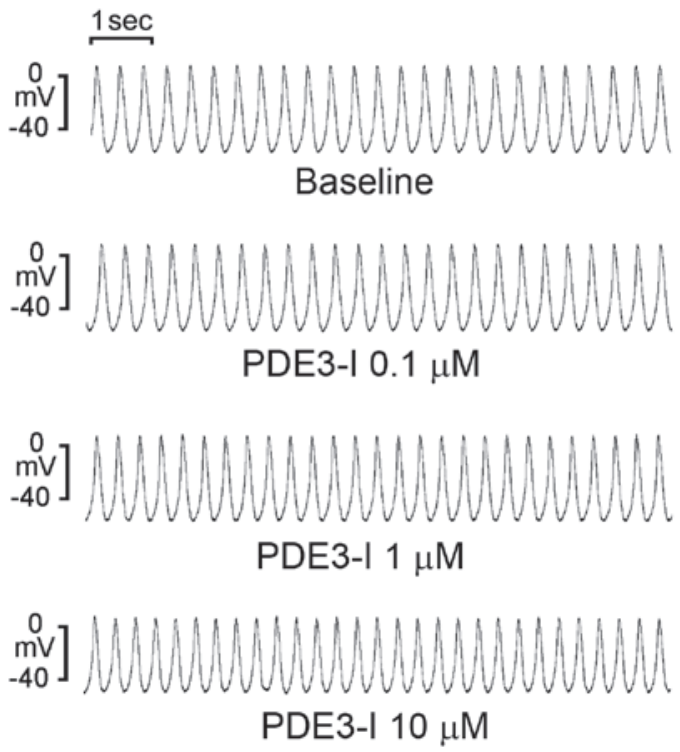

口Baseline $\quad$ m PDE3-I $1 \mu \mathrm{M}$

- PDE3-I $0.1 \mu \mathrm{M}$ = PDE3-I $10 \mu \mathrm{M}$

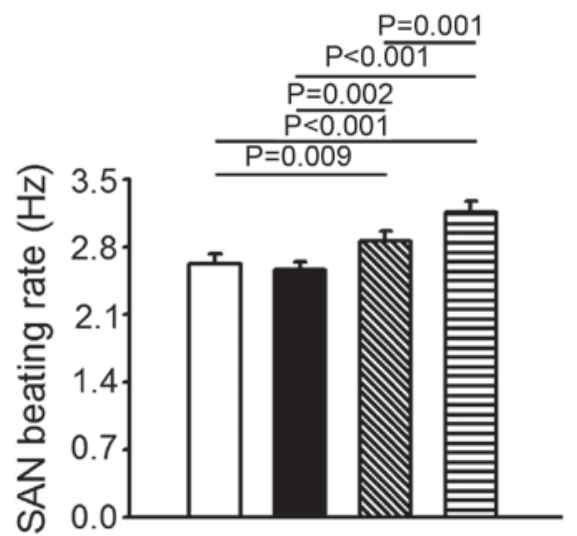

Figure 2. Effects of the PDE3 inhibitor (PDE3-I), milrinone, on the electrical activity of isolated SANs. Representative data of the beating rate after the application of different concentrations $(0.1,1$ and $10 \mu \mathrm{M})$ of the PDE3-I on SANs ( $n=7)$. PDE3, phosphodiesterase 3; SAN, sinoatrial node.

variables were compared by a $\chi^{2}$ analysis with Fisher's exact test. $\mathrm{P}<0.05$ was considered to indicate a statistically significant difference. Statistical analysis was performed using SigmaPlot software (version 12.0; Systat Software, Inc.).

\section{Results}

Effects of the PDE3 inhibitor on the electrical activities of isolated PVs and SANs. The PDE3 inhibitor (milrinone; 1 and $10 \mu \mathrm{M})$ significantly increased PV spontaneous activity by $10.6 \pm 4.9 \%(\mathrm{P}=0.018)$ and $16.7 \pm 5.3 \%(\mathrm{P}<0.001)$ and contractility by $31.7 \pm 9.8 \%(\mathrm{P}=0.019)$ and $58.8 \pm 19 \%$ $(\mathrm{P}<0.001)$ compared with the baseline, respectively, but had no significant effect on the diastolic tension of PVs (Fig. 1A). Milrinone also significantly increased PV diastolic tension by $8.9 \pm 3.7 \%(\mathrm{P}=0.002)$ at $10 \mu \mathrm{M}$. Moreover, milrinone $(\geq 1 \mu \mathrm{M})$ induced triggered activity including EAD, or DAD or burst firing in PVs ( $0 / 8$ vs. $5 / 8$; $\mathrm{P}<0.05$; Fig. 1B). Similarly, the PDE3 inhibitor increased SAN activity by $9.3 \pm 4.3 \%$ and $20.7 \pm 4.6 \%$ at 1 and $10 \mu \mathrm{M}$ compared with the baseline, respectively (Fig. 2). However, milrinone did not induce burst firing in SANs.

Application of KT5823 $(1 \mu \mathrm{M})$, a selective PKG inhibitor, abolished milrinone-accelerated PV electrical activity (Fig. 3A). In addition, H89 $(10 \mu \mathrm{M})$, a PKA inhibitor, also suppressed milrinone-accelerated PV electrical activity (Fig. 3B). Isoproterenol increased PV spontaneous activity, diastolic tension (Fig. 3B) and the occurrence of burst firing compared with the baseline (4/5 vs. 0/5; $\mathrm{P}<0.05$; Fig. $3 \mathrm{C})$. However, in the presence of isoproterenol, milrinone $(10 \mu \mathrm{M})$ did not significantly alter the PV spontaneous activity or diastolic tension $(\mathrm{P}>0.05)$ compared with the baseline. Taken together, PDE3 inhibition may regulate PV electrical activity through adrenergic activity and activation of the PKG and PKA signaling pathways.

Effects of the PDE4 inhibitor on the electrical activities of isolated PVs and SANs. The PDE4 inhibitor (rolipram; 0.1, 1 and $10 \mu \mathrm{M}$ ) increased PV spontaneous activity by $7.5 \pm 1.3$, $8.2 \pm 3.1$ and $9.5 \pm 4 \%$, PV diastolic tension by $1.6 \pm 4.7,6.8 \pm 5.9$ and $7.4 \pm 5.8 \%$, and PV contractility by $11.7 \pm 3.8,23.8 \pm 3.1$ and $32.3 \pm 7.5 \%$ compared with the baseline, respectively (Fig. 4A). Rolipram $(0.1,1$ and $10 \mu \mathrm{M})$ did not significantly alter SAN activity compared with the baseline (Fig. 4B), and there was only one triggered beat in rolipram-treated $\mathrm{PVs}$ and none in rolipram-treated SANs (1/6 vs. 0/6; P>0.05).

Effects of the PDE5 inhibitor on the electrical activities of isolated PVs and SANs. The PDE5 inhibitor, sildenafil, significantly reduced PV spontaneous activity by $13.5 \pm 5.5 \%$ at $1 \mu \mathrm{M}$ and $25.9 \pm 9 \%$ at $10 \mu \mathrm{M}$ compared with the baseline $(\mathrm{P}<0.05$; Fig. 5A). Sildenafil $(0.1,1$ and $10 \mu \mathrm{M})$ significantly reduced PV contractility by $16.6 \pm 4.6 \%(\mathrm{P}=0.013), 27.5 \pm 7.0 \%$ $(\mathrm{P}<0.001)$ and $31.2 \pm 6.0 \%(\mathrm{P}<0.001)$, respectively, but increased PV diastolic tension by $10.3 \pm 4.1 \%(\mathrm{P}=0.035)$, $15.5 \pm 4.9 \%(\mathrm{P}=0.004)$ and $17.8 \pm 6.7 \%(\mathrm{P}=0.002)$, respectively, compared with the baseline, respectively. Moreover, the isoproterenol-induced accelerated PV spontaneous activity was attenuated by sildenafil (Fig. 5B). In addition, sildenafil suppressed isoproterenol-induced PV burst firing from 66.7 to $0 \%(\mathrm{P}<0.001 ; \mathrm{n}=9$; Fig. 5B). Sildenafil $(0.1,1$ and $10 \mu \mathrm{M})$ reduced SAN activity compared with the baseline, however, at $10 \mu \mathrm{M}$ sildenafil reduced SAN activity by $9.7 \%$, which was less than the effect of sildenafil on PVs (Fig. 6).

\section{Discussion}

HF is a common risk factor for AF (2-4). Milrinone potentiates the effect of cyclic adenosine monophosphate (cAMP) and enhances the relaxation of the left ventricle by increasing $\mathrm{Ca}^{2+}$-ATPase activity in the cardiac sarcoplasmic reticulum, by increasing calcium ion uptake (7). Although the PDE3 inhibitor, milrinone, improves HF through positive inotropic effects, milrinone also increases the risk of AF in patients with HF (13). In the present study, milrinone increased PV and SAN spontaneous activities to a similar extent. The accelerating effect of milrinone on PVs was abolished by the PKG inhibitor (KT5823; $1 \mu \mathrm{M}$ ) and the PKA inhibitor (H89; $10 \mu \mathrm{M}$ ), suggesting that the electrophysiological effects of 

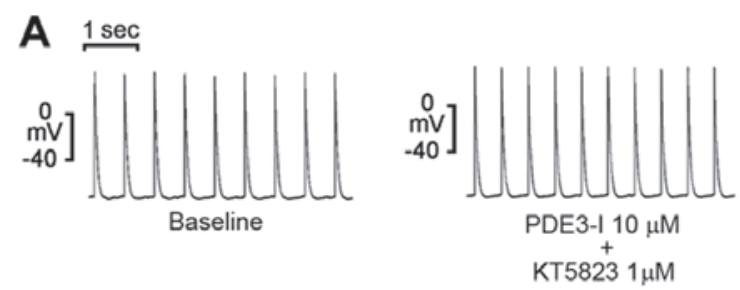

๑Baseline

-PDE3-I $10 \mu \mathrm{M}$

a. PDE3-I $10 \mu \mathrm{M}+\mathrm{KT} 58231 \mu \mathrm{M}$

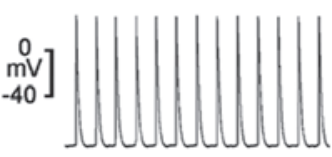

PDE3-I $10 \mu \mathrm{M}$
B
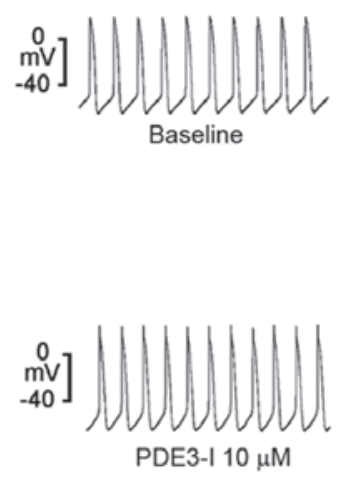

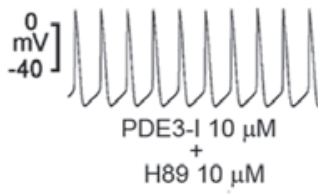

-Baseline

- PDE3-I $10 \mu \mathrm{M}$

m PDE3-I $10 \mu \mathrm{M}+\mathrm{H} 8910 \mu \mathrm{M}$

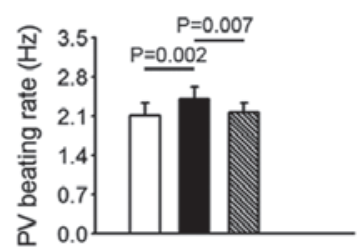

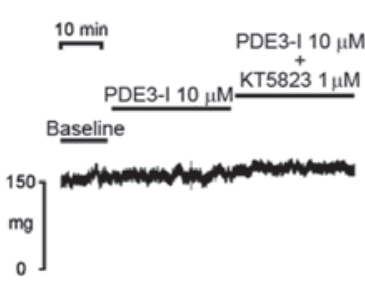
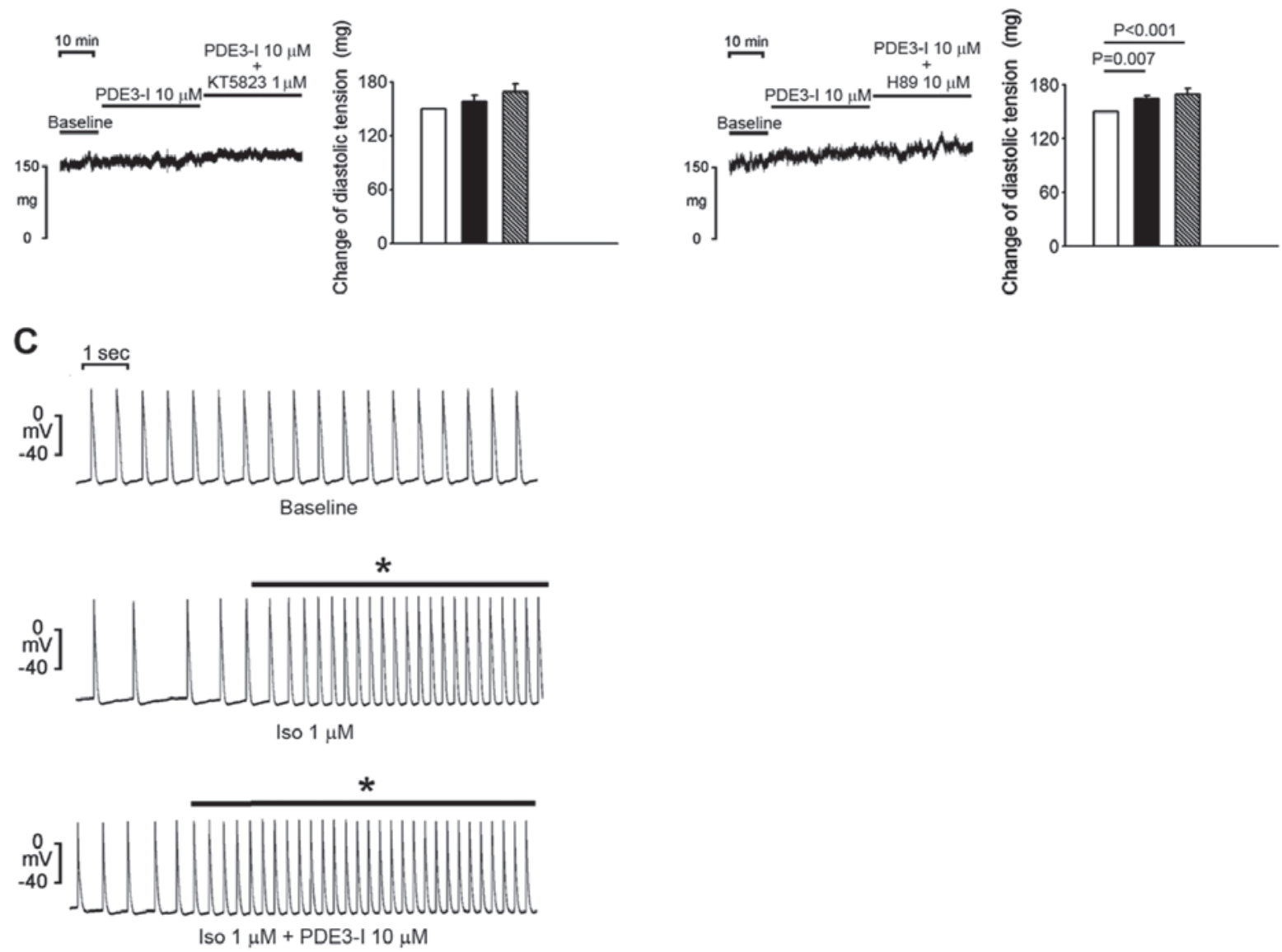

Figure 3. Effects of the protein kinase G inhibitor, KT5823, and the protein kinase A inhibitor, H89, on PDE3 inhibitor (PDE3-I)-modulated electrical activity of isolated PVs. (A) Representative data of the beating rate and diastolic tension of PVs after the application of $10 \mu \mathrm{M}$ PDE3-I, milrinone, and $1 \mu \mathrm{M}$ KT5823. (B) Representative data of the beating rate and diastolic tension of PVs after the application of $10 \mu \mathrm{M}$ PDE3-I and 10 $\mu \mathrm{M}$ H89. (C) Examples of burst firing (asterisks) in PVs after the administration of $1 \mu \mathrm{M}$ isoproterenol and $10 \mu \mathrm{M}$ PDE3-I. PDE3, phosphodiesterase 3; PV, pulmonary vein; Iso, isoproterenol.

milrinone could involve the PKG and PKA signaling pathways. Additionally, the effect of milrinone on PV arrhythmogenesis in the presence of isoproterenol indicated that milrinone and isoproterenol might regulate PV electrical activity in a similar manner, via the activation of cAMP.

Previous studies reported that milrinone might relax the pulmonary arterial and venous vascular beds in guinea pig and human lung tissues by activating the ATP-sensitive potassium channel $(30,31)$. However, the present study suggested that milrinone increased diastolic tension in PVs. The discrepancy may have been caused by the differences between distal, with simple venous structures, and proximal PVs, since the atrial-PV junction used in the present study contained the myocardial sleeve surrounding the PV vascular components. Milrinone may increase PV diastolic tension via positive inotropic effects on cardiomyocytes, as shown by increased PV contractility. 

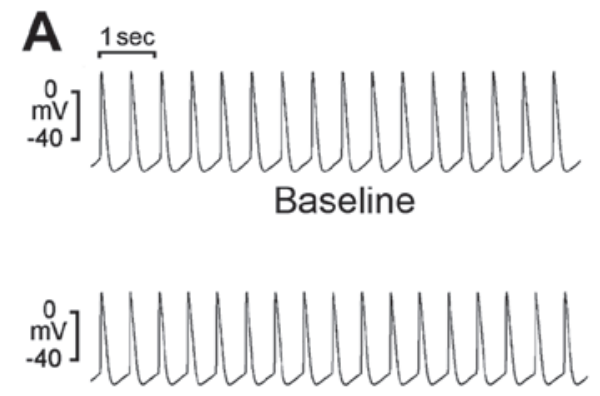

PDE4-I $0.1 \mu \mathrm{M}$
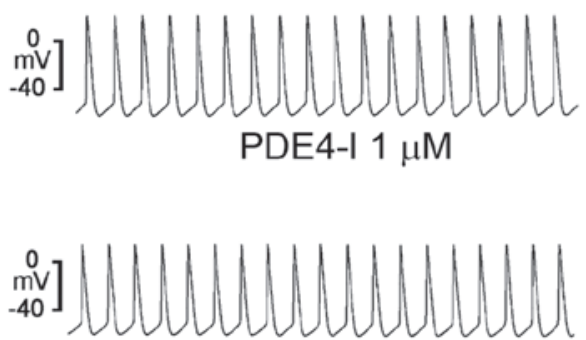

PDE4-I $10 \mu \mathrm{M}$

$\begin{array}{ll}\text { 口Baseline } & \text { mDE4-I } 1 \mu \mathrm{M} \\ \text {-PDE4-I } 0.1 \mu \mathrm{M} & \text { aPDE4-I } 10 \mu \mathrm{M}\end{array}$

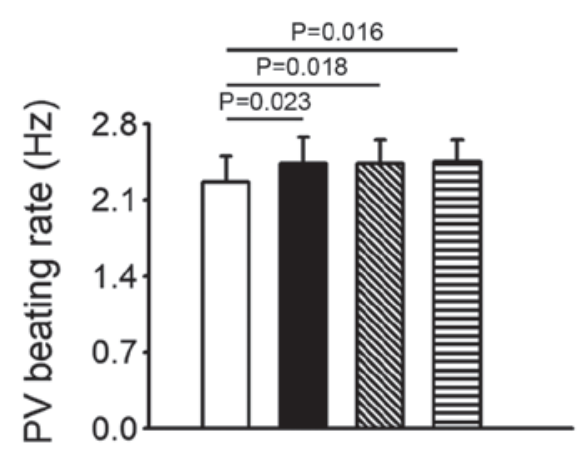

B $1 \mathrm{sec}$

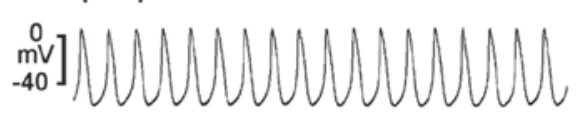

Baseline
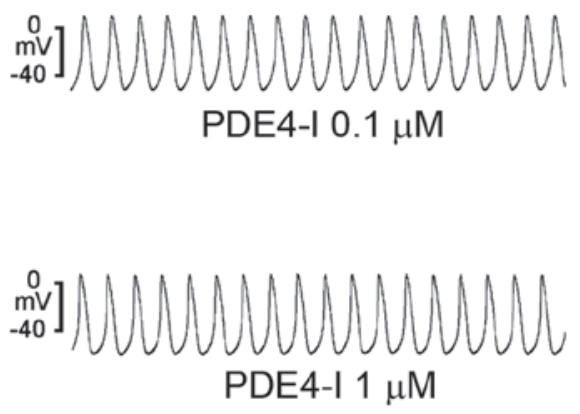
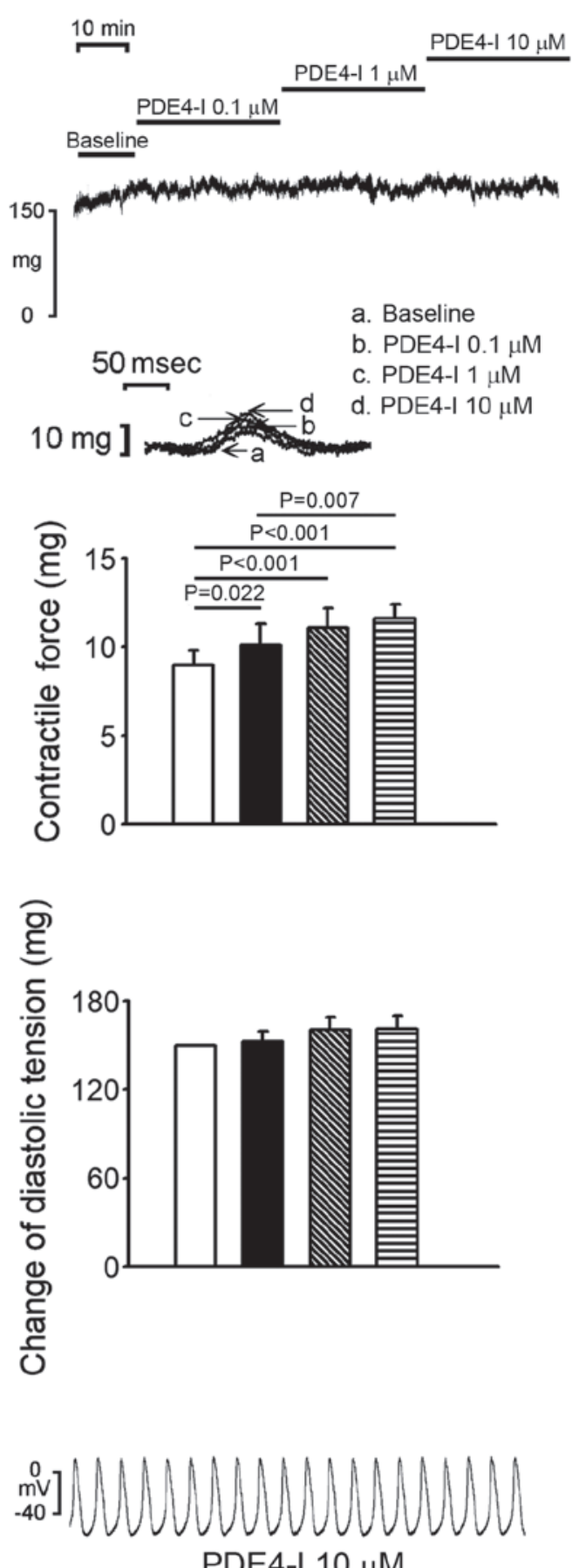

PDE4-I $10 \mu \mathrm{M}$

$$
\begin{array}{ll}
\text { 口Baseline } & \text { a PDE4-I } 1 \mu \mathrm{M} \\
\text {-PDE4-I } 0.1 \mu \mathrm{M} & \text { =PDE4-I } 10 \mu \mathrm{M}
\end{array}
$$

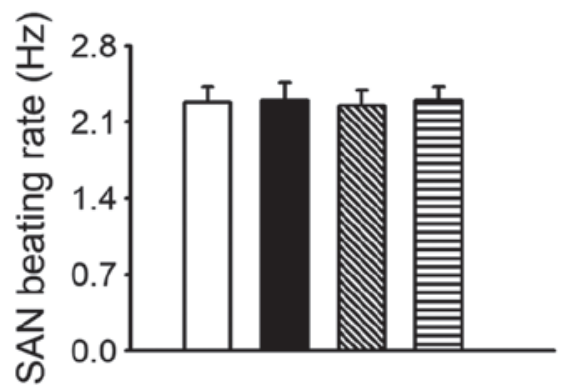

Figure 4. Effects of the PDE4 inhibitor (PDE4-I), rolipram, on the electrical activities of isolated PVs and SANs. (A) Representative data of the beating rate, diastolic tension and contractility of PVs after the application of different concentrations $(0.1,1$ and $10 \mu \mathrm{M})$ of the PDE4-I $(\mathrm{n}=6)$. (B) Representative data of the beating rate of SANs after the application of different concentrations $(0.1,1$ and $10 \mu \mathrm{M})$ of the PDE4-I (n=6). PDE4, phosphodiesterase 4; PV, pulmonary vein; SAN, sinoatrial node. 
A
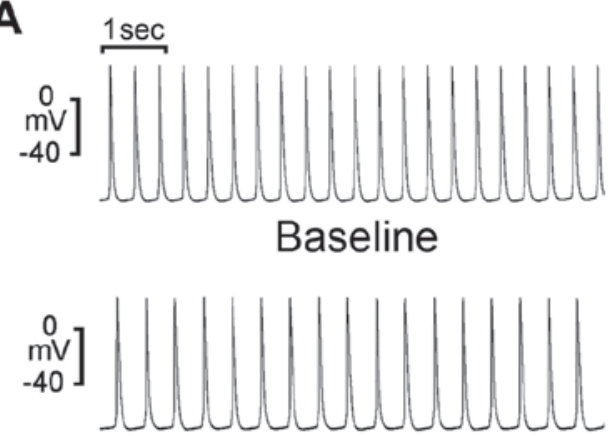

PDE5-I $0.1 \mu \mathrm{M}$

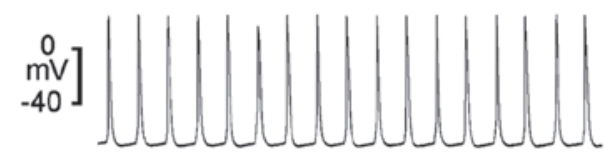

PDE5-I $1 \mu \mathrm{M}$

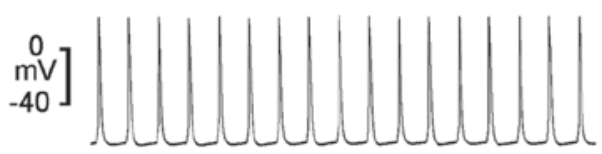

PDE5-I $10 \mu \mathrm{M}$

口Baseline mDE5-I $1 \mathrm{mM}$

-PDE5-I $0.1 \mu \mathrm{M}$ =PDE5-I $10 \mu \mathrm{M}$

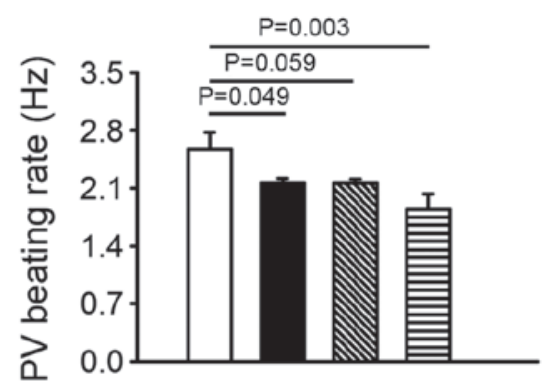

B $1 \mathrm{sec}$

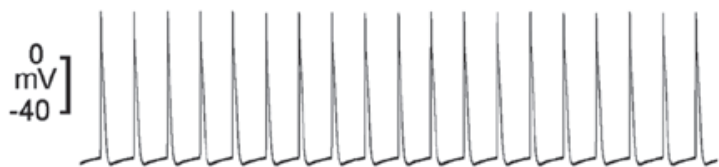

Baseline

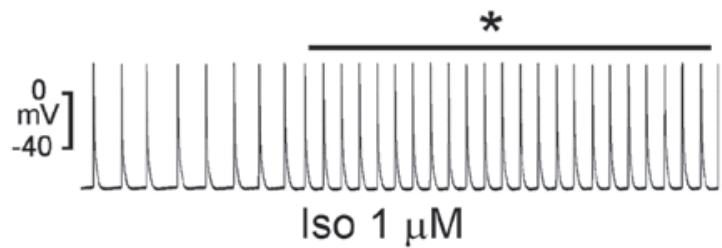

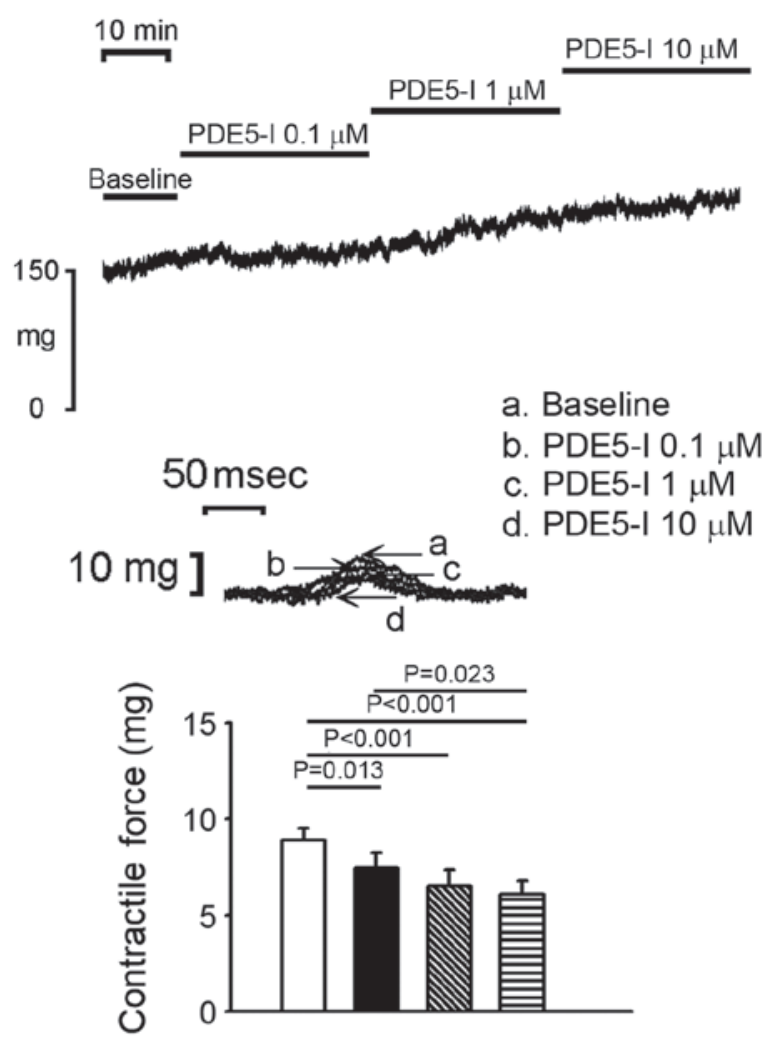
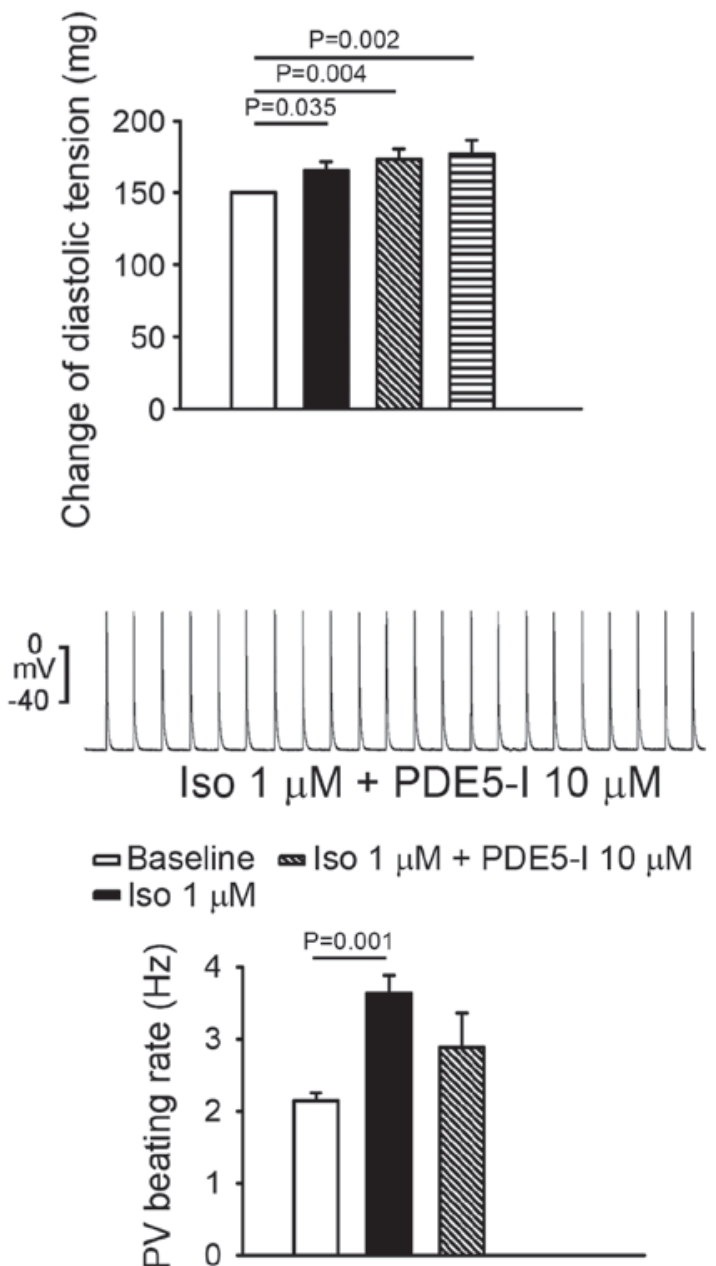

Figure 5. Effects of the PDE5 inhibitor (PDE5-I), sildenafil, on the electrical activity of isolated PVs. (A) Representative data of the beating rate, diastolic tension and contractility of PVs after the application of different concentrations ( $0.1,1$ and $10 \mu \mathrm{M})$ of the PDE5-I (n=7). (B) Examples of burst firing (asterisks) in PVs after the application of $1 \mu \mathrm{M}$ isoproterenol and $10 \mu \mathrm{M}$ PDE5-I (1 $\mu \mathrm{M}$; $\mathrm{n}=9)$. PDE5, phosphodiesterase 5; PV, pulmonary vein; Iso, isoproterenol. 

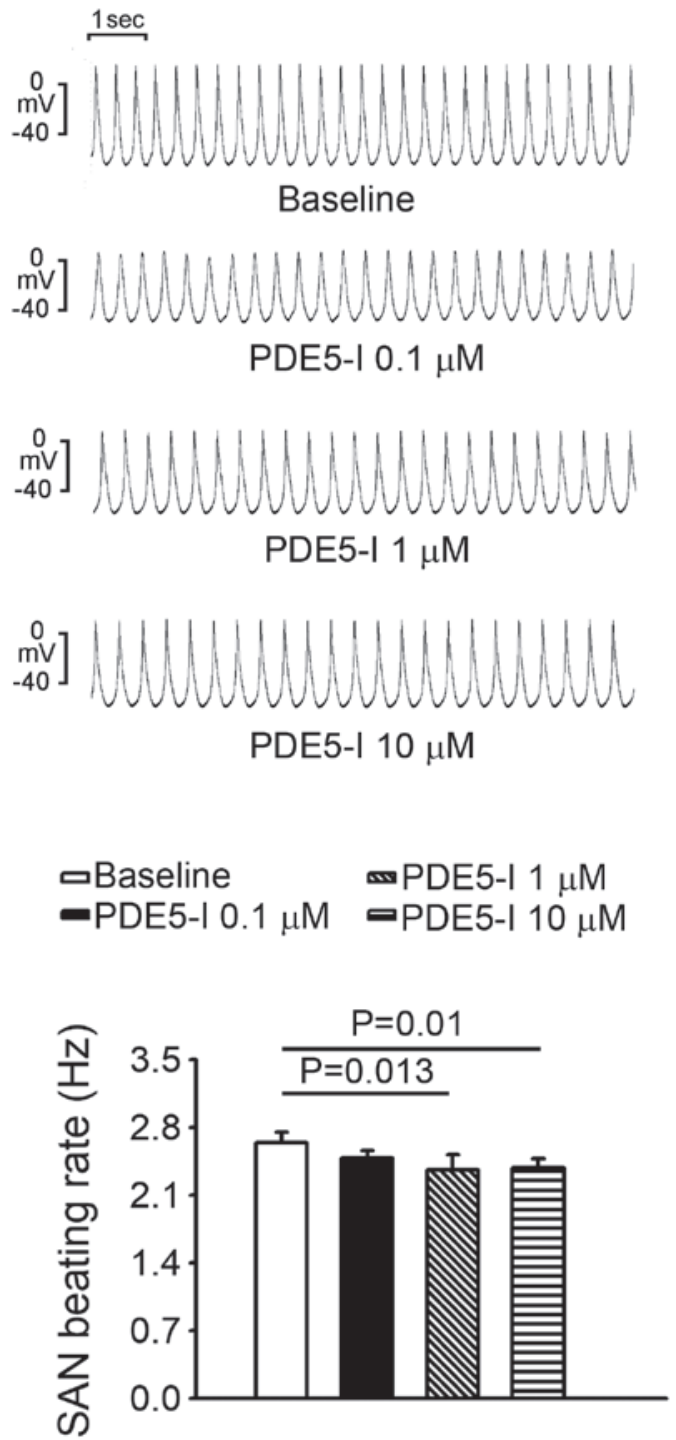

Figure 6. Effects of the PDE5 inhibitor (PDE5-I), sildenafil, on the electrical activity of isolated SANs. Representative data of the beating rate of SANs after the application of different concentrations $(0.1,1$ and $10 \mu \mathrm{M})$ of the PDE5-I (n=7). PDE5, phosphodiesterase 5; SAN, sinoatrial node.

PDE4 inhibition increased intracellular cAMP levels and the $\mathrm{I}_{\mathrm{Ca-L}}$ in atrial myocytes, as well as increasing the frequency of spontaneous $\mathrm{Ca}^{2+}$ release (18), which may predispose individuals to AF. However, in the present study, the PDE4 inhibitor, rolipram, had no significant effect on PV and SAN spontaneous activities. The results from the present study were consistent with that of a previous study, which suggested that PDE4 inhibition did not significantly alter SAN electrical activity (32). Therefore, clinical observations of an increased risk of AF in patients receiving PDE4 inhibition therapy might be explained by AF substrate modifications, rather than the enhancement of the arrhythmogenesis that AF triggers (33).

PDE5 expression is strongly increased in HF (34-36). Previous studies reported that inhibition of PDE5 ameliorates cardiac dysfunction and sildenafil blocks $\mathrm{I}_{\mathrm{Ca}-\mathrm{L}}$ in ventricular myocytes in a dose-dependent manner (18). In the present study, sildenafil significantly reduced PV and SAN spontaneous activities. The stronger inhibitory effect of sildenafil on PV activity compared with SAN activity might reduce the risk of AF. The rate reduction effect of sildenafil on PVs may be partially attributed to the NO synthase-mediated signaling pathways, since NO has been shown to play an important role in PV arrhythmogenesis (37). Sildenafil increased the PV diastolic tension, but decreased PV contractility, which may be accounted for by the electrophysiological effects of sildenafil via mechanoelectrical feedback. Contrastingly to PDE3 inhibitors, which exhibit a high affinity for both cAMP and cGMP, sildenafil, as a cGMP-specific PDE5 blocker (7), abolished isoproterenol-induced increases in PV activity. This result was in line with a previous report, which indicated that sildenafil can attenuate $\beta$-receptor agonist-induced cAMP generation and accelerate the beating rate of PVs (38). Similar to the present study, PDE5 inhibition was previously reported to have a negative chronotropic effect on mice SANs (26). Accordingly, sildenafil may potentially protect individuals from $\mathrm{AF}$ by reducing $\mathrm{PV}$ arrhythmogenesis.

Acute infusion of the kinase inhibitors, including KT5823 and $\mathrm{H} 89$, was performed in the present study to investigate the effect of milrinone on PVs. The suppression of the PDE3 accelerating effect on PVs following acute infusion of the kinase inhibitors suggested a role for the cGMP and PKA signaling pathways in PDE3 inhibitor mediated PV arrhythmogenesis. However, it is not clear whether the PDE inhibitors may have further unknown effects or whether the kinase inhibitors exert their effects at the cellular level. Since only the acute effects of the kinase inhibitors were evaluated in the present study, the protein expression of components of the cGMP and PKA signaling pathways in PVs at such a short exposure time is highly unlikely to be affected or to be shown by western blot analysis. Therefore, this requires further investigation.

In conclusion, different subtypes of PDE inhibitors regulate PV and SAN electrical activities in distinct manners and may contribute to susceptibility to atrial arrhythmogenesis.

\section{Acknowledgements}

Not applicable.

\section{Funding}

The present study was supported by the Ministry of Science and Technology (grant nos. MOST105-2314-B-016 -035-MY3, MOST105-2628-B-038-012-MY3, MOST1052314-B-038-059-MY3, MOST106-2314-B-038-060 and MOST107-2314-B-038-101-MY3), the Taipei Medical University-Wan Fang Hospital (grant nos. 105-wf-eva-06, 105-swf-02, 105-wf-eva-08, 105-wf-eva-14, 106-eva-02, 106-eva-06, 106-swf-01, 107-wf-swf-02 and 107-wf-eva-13), the Cathay General Hospital (grant no. 106CGH-TMU-04), the Chi-Mei Medical Center (grant nos. 106CM-TMU-08 and CMNDMC10606) and the Ministry of National Defense-Medical Affairs Bureau (grant no. MAB-107-044).

\section{Availability of data and materials}

The datasets used and/or analyzed during the present study are available from the corresponding author on reasonable request. 


\section{Authors' contributions}

YKL and CCC contributed to the experimental design, performed the in vitro experiments, analyzed the experimental results and wrote the paper. YKL and JHH and gave various contributions in the statistical analysis, and interpretation of the results and discussion. YAC contributed to the in vitro experiments and provided technical assistance in the study. SAC and YJC contributed to the experimental design, analysis of the results and final revision of the paper for publication. YYL and YCC conceived and designed the study, and reviewed the paper prior to submission.

\section{Ethics approval and consent to participate}

The present study was approved of the Institutional Animal Care and Use Committee by the local review board (approval no. IACUC-19-124) of the National Defense Medical Center, Taipei, Taiwan and conformed to the institutional Guide for the Care and Use of Laboratory Animals and the 'Guide for the Care and Use of Laboratory Animals' published by the United States National Institutes of Health (8 ed. Washington DC, 2011).

\section{Patient consent for publication}

Not applicable.

\section{Competing interests}

The authors declare that they have no competing interests.

\section{References}

1. Tsang TS and Gersh BJ: Atrial fibrillation: An old disease, a new epidemic. Am J Med 113: 432-435, 2002.

2. Schotten U, Neuberger HR and Allessie MA: The role of atrial dilatation in the domestication of atrial fibrillation. Prog Biophys Mol Biol 82: 151-162, 2003.

3. Chang SL, Chen YC, Chen YJ, Wangcharoen W, Lee SH, Lin CI and Chen SA: Mechanoelectrical feedback regulates the arrhythmogenic activity of pulmonary veins. Heart 93: 82-88, 2007.

4. Sanders P, Morton JB, Davidson NC, Spence SJ, Vohra JK, Sparks PB and Kalman JM: Electrical remodeling of the atria in congestive heart failure: Electrophysiological and electroanatomic mapping in humans. Circulation 108: 1461-1468, 2003.

5. Li D, Melnyk P, Feng J, Wang Z, Petrecca K, Shrier A and Nattel S: Effects of experimental heart failure on atrial cellular and ionic electrophysiology. Circulation 101: 2631-2638, 2000.

6. Yeh YH, Wakili R, Qi XY, Chartier D, Boknik P, Kääb S, Ravens U, Coutu P, Dobrev D and Nattel S: Calcium-handling abnormalities underlying atrial arrhythmogenesis and contractile dysfunction in dogs with congestive heart failure. Circ Arrhythm Electrophysiol 1: 93-102, 2008.

7. Knight W and Yan C: Therapeutic potential of PDE modulation in treating heart disease. Future Med Chem 5: 1607-1620, 2013.

8. Miller CL and Yan C: Targeting cyclic nucleotide phosphodiesterase in the heart: Therapeutic implications. J Cardiovasc Transl Res 3: 507-515, 2010.

9. Jaski BE, Fifer MA, Wright RF, Braunwald E and Colucci WS: Positive inotropic and vasodilator actions of milrinone in patients with severe congestive heart failure. Dose-response relationships and comparison to nitroprusside. J Clin Invest 75: 643-649, 1985.

10. Omori K and Kotera J: Overview of PDEs and their regulation. Circ Res 100: 309-327, 2007.

11. Varma A, Shah KB and Hess ML: Phosphodiesterase inhibitors, congestive heart failure, and sudden death: Time for re-evaluation. Congest. Heart Fail 18: 229-233, 2012.
12. Ghosh R, Sawant O, Ganpathy P, Pitre S and Kadam VJ: Phosphodiesterase inhibitors: Their role and implications. Int $\mathrm{J}$ PharmTech Res 1: 1148-1160, 2009.

13. Cuffe MS, Califf RM, Adams KF Jr, Benza R, Bourge R, Colucci WS, Massie BM, O'Connor CM, Pina I, Quigg R, et al: Outcomes of a prospective trial of intravenous milrinone for exacerbations of chronic heart failure (OPTIME-CHF) Investigators. Short term intravenous milrinone for acute exacerbation of chronic heart failure: A randomized controlled trial JAMA 287: 1541-1547, 2002.

14. Wechsler J, Choi YH, Krall J, Ahmad F, Manganiello VC and Movsesian MA: Isoforms of cyclic nucleotide phosphodiesterase PDE3A in cardiac myocytes. J Biol Chem 277: 38072-38078, 2002.

15. Bevan S, Porteous L, Sitzer M and Markus HS: Phosphodiesterase 4D gene, ischemic stroke, and asymptomatic carotid atherosclerosis. Stroke 36: 949-953, 2005.

16. Milton AG, Aykanat VM, Hamilton-Bruce MA, Nezic M, Jannes $J$ and Koblar SA: Association of the phosphodiesterase 4D (PDE4D) gene and cardioembolic stroke in an Australian cohort. Int J Stroke 6: 480-486, 2011.

17. Calverley PM, Rabe KF, Goehring UM, Kristiansen S, Fabbri LM and Martinez FJ: Roflumilast in symptomatic chronic obstructive pulmonary disease: Two randomised clinical trials. Lancet 374: 685-694, 2009.

18. Chiang CE, Luk HN, Wang TM and Ding PY: Effects of sildenafil on cardiac repolarization. Cardiovasc Res 55: 290-299, 2002.

19. Dustan Sarazan R, Crumb WJ Jr, Beasley CM Jr, Emmick JT, Ferguson KM, Strnat CA and Sausen PJ: Absence of clinically important HERG channel blockade by three compounds that inhibit phosphodiesterase-5-sildenafil, tadalafil, and vardenafil. Eur J Pharmacol 502: 163-167, 2004.

20. Swissa M, Ohara T, Lee MH, Kaul S, Shah PK, Hayashi H, Chen PS and Karagueuzian HS: Sildenafil-nitric oxide donor combination promotes ventricular tachyarrhythmias in the swine right ventricle. Am J Physiol Heart Circ Physiol 282: H1787-H1792, 2002.

21. Chen YJ and Chen SA: Electrophysiology of pulmonary veins. J Cardiovasc Electrophysiol 17: 220-224, 2006.

22. Honjo H, Boyett MR, Niwa R, Inada S, Yamamoto M, Mitsui K, Horiuchi T, Shibata N, Kamiya K and Kodama I: Pacing-induced spontaneous activity in myocardial sleeves of pulmonary veins after treatment with ryanodine. Circulation 107: 1937-1943, 2003.

23. Patterson E, Lazzara R, Szabo B, Liu H, Tang D, Li YH, Scherlag BJ and Po SS: Sodium-calcium exchange initiated by the $\mathrm{Ca} 2+$ transient: An arrhythmia trigger within pulmonary veins. J Am Coll Cardiol 47: 1196-1206, 2006.

24. Chen SA, Hsieh MH, Tai CT, Tsai CF, Prakash VS, Yu WC, Hsu TL, Ding YA and Chang MS: Initiation of atrial fibrillation by ectopic beats originating from the pulmonary veins: Electrophysiological characteristics, pharmacological responses, and effects of radiofrequency ablation. Circulation 100: 1879-1886, 1999

25. Chen YJ, Chen SA, Chen YC, Yeh HI, Chan P, Chang MS and Lin CI: Effects of rapid atrial pacing on the arrhythmogenic activity of single cardiomyocytes from pulmonary veins: Implication in initiation of atrial fibrillation. Circulation 104: 2849-2854, 2001

26. Lu YY, Lin YK, Wen ZH, Chen YC, Chen SA and Chen YJ: Latrunculin B modulates electrophysiological characteristics and arrhythmogenesis in pulmonary vein cardiomyocytes. Clin Sci 130: 721-732, 2016.

27. Chang SL, Hsiao YW, Tsai YN, Lin SF, Liu SH, Lin YJ, Lo LW, Chung FP, Chao TF, Hu YF, et al: Interleukin-17 enhances cardiac ventricular remodeling via activating MAPK pathway in ischemic heart failure. J Mol Cell Cardiol 122: 69-79, 2018.

28. Pelizzo G, Avanzini MA, Icaro Cornaglia A, Osti M, Romano P, Avolio L, Maccario R, Dominici M, De Silvestri A, Andreatta E, et al: Mesenchymal stromal cells for cutaneous wound healing in a rabbit model: Pre-clinical study applicable in the pediatric surgical setting. J Transl Med 13: 219, 2015.

29. Lu YY, Cheng CC, Wu HJ, Lin YK, Chen YC, Chen SA and Chen YJ: Effects of ANP on pulmonary vein electrophysiology, $\mathrm{Ca} 2+$ homeostasis and adrenergic arrhythmogenesis via PKA. Clin Exp Pharmacol Physiol 47: 247-254, 2020.

30. Rieg AD, Suleiman S, Perez-Bouza A, Braunschweig T, Spillner JW, Schröder T, Verjans E, Schälte G, Rossaint R, Uhlig S and Martin C: Milrinone relaxes pulmonary veins in guinea pigs and humans. PLoS One 9: e87685, 2014. 
31. Kato R, Sato J and Nishino T: Milrinone decreases both pulmonary arterial and venous resistances in the hypoxic dog. Br J Anaesth 81: 920-924, 1998.

32. Vinogradova TM, Sirenko S, Lukyanenko YO, Yang D, Tarasov KV, Lyashkov AE, Varghese NJ, Li Y, Chakir K, Ziman B and Lakatta EG: Basal spontaneous firing of rabbit sinoatrial node cells is regulated by dual activation of PDEs (Phosphodiesterases) 3 and 4. Circ Arrhythm Electrophysiol 11: e005896, 2018.

33. Van Wagoner DR and Lindsay BD: Phosphodiesterase-4 activity: A critical modulator of atrial contractility and arrhythmogenesis. J Am Coll Cardiol 59: 2191-2192, 2012.

34. Lu Z, Xu X, Hu X, Lee S, Traverse JH, Zhu G, Fassett J, Tao Y, Zhang P, dos Remedios C, et al: Oxidative stress regulates left ventricular PDE5 expression in the failing heart. Circulation 121: 1474-1483, 2010.
35. Nagendran J, Archer SL, Soliman D, Gurtu V, Moudgil R, Haromy A, St Aubin C, Webster L, Rebeyka IM, Ross DB, et al: Phosphodiesterase type 5 is highly expressed in the hypertrophied human right ventricle, and acute inhibition of phosphodiesterase type 5 improves contractility. Circulation 116: 238-248, 2007.

36. Hwang IC, Kim YJ, Park JB, Yoon YE, Lee SP, Kim HK, Cho GY and Sohn DW: Pulmonary hemodynamics and effects of phosphodiesterase type 5 inhibition in heart failure: A meta-analysis of randomized trials. BMC Cardiovasc Disord 17: 150,2017

37. Lin YK, Lu YY, Chen YC, Chen YJ and Chen SA: Nitroprusside modulates pulmonary vein arrhythmogenic activity. J Biomed Sci 17: 20, 2010.

38. Isidori AM, Cornacchione M, Barbagallo F, et al: Inhibition of type 5 phosphodiesterase counteracts $\beta 2$-adrenergic signalling in beating cardiomyocytes. Cardiovasc Res 106: 408-420, 2015. 